Noman 2016, 34(2), 37-48

Revista de Psicologia, Ciències de l’Educació i de l'Esport

ISSN: 1138-3194

Copyright (c) 2016

www.revistaaloma.net

\title{
Xarxes, accelerometria i anticipació en l'esport dins l'entorn lliure Chronojump
}

\author{
Xavier de Blas ${ }^{1,2}$ Jordi Carreras ${ }^{1}$, Ferran Suárez ${ }^{1}$, Xavier Padullés², Francesc Hernández ${ }^{1}$ \\ 'Universitat Ramon Llull \\ 2Projecte Chronojump-Boscosystem
}

Rebut: 22-5-2016

Acceptat: 29-9-2016

\section{Xarxes, accelerometria i anticipació en l'esport dins l'entorn lliure Chronojump}

Resum. El projecte Chronojump va iniciar-se com a solució per a la mesura del salt vertical a partir de plataforma de contactes. Posteriorment s'hi van integrar fotocèl-lules i encoders. A causa de la naturalesa lliure del projecte, és viable afegir-hi funcionalitats que en el mercat privatiu són incompletes i costoses. Les solucions que es desenvolupen són aquestes: un entorn centralitzat de dades de diferents estacions de treball en gimnasos o clubs, un dispositiu d'accelerometria triaxial i un sistema per a la mesura del temps de reacció electiu, anticipació i flicker. Els mètodes són els següents: entrevistes a experts, desenvolupament de l'acceleròmetre i dispositius per a la mesura del temps de reacció, proves de velocitat $i$ temperatura en miniordinadors, proves ideals i manuals de l'acceleròmetre, proves de la velocitat dels leds en el dispositiu d'anticipació, i proves d'anticipació en una mostra. Els resultats indiquen que el miniordinador més adient és el Raspberry Pi; es troben valors perfectes en l'accelerometria ideal però força erronis en la manual a causa de la impuresa del moviment humà; l'errada en la velocitat dels leds en l'anticipació és del 0,03\%, i es troben diferències significatives entre els grups visual, auditiu i electiu. Les tres aportacions són públiques per facilitar la recerca en les ciències de l'esport.

Paraules clau: Chronojump; programari lliure; xarxa; accelerometria; temps de reacció

\section{Networks, accelerometry and anticipation in sports in Chronojump free environment}

Summary. The Chronojump project started as a solution for measuring vertical jumps using a contact platform. Photocells and encoders were added later. Being a free project, it's possible to add new features would be costly and incomplete if purchased separately on the market. Among the solutions being developed are: a centralized data environment for the workstations at gyms / clubs, a triaxial accelerometer and a device for measuring discriminative reaction time, anticipation and flicker. The methods employed include interviews with experts, the development of the accelerometer and reaction time devices, speed and temperature tests on minicomputers, ideal and manual accelerometer tests, LED speed tests on the anticipation device and anticipation tests on a sample. Results point to Raspberry Pi as the most suitable minicomputer, achieving perfect values for ideal accelerometry but exhibiting considerable errors in the manual test case due to the impurity of human movement. There was an anticipation error of around $0.03 \%$ on LED speed, significant differences between visual, auditory and elective stimulus on anticipation tests. The three contributions are public in order to facilitate research in sports science.

Keywords: Chronojump; free software; network; accelerometer; reaction time

\author{
Correspondència: \\ Xavier de Blas \\ Facultat de Psicologia, Ciències de l'Educació i de l'Esport \\ Blanquerna \\ Universitat Ramon Llull \\ c/Císter 34 08022, Barcelona. \\ francescxavierdf@blanquerna.url.edu
}




\section{Introducció}

El projecte Chronojump-Boscosystem (Chronojump, 2016) és un conjunt d'eines de programari i maquinari lliure per a la mesura de paràmetres cinemàtics i dinàmics de tests esportius de curta durada. La primera versió del seu programari (anomenat Chronojump) és va publicar l'any 2004, i es va actualitzant regularment. Per tal de garantir la fiabilitat, les mesures es realitzen sempre en el microcontrolador que es va construir a tal efecte l'any 2005 i que també ha rebut actualitzacions. Aquest microcontrolador s'anomena Chronopic. La llibertat d'ambdues eines permet que, en contraposició al programari privatiu, qualsevol les pugui usar per a qualsevol propòsit, estudiar i adaptar a les pròpies necessitats, distribuir, i distribuir amb les millores que s'hagin efectuat (Stallman i col., 2002); en tots els casos sense estar subjectes a aranzels ni patents. Himanen (2001) afirma que aquestes característiques es corresponen amb el model obert de la ciència, model que ha demostrat ser la millor manera de crear informació. Les obligacions de la seva ètica són aquestes: Les fonts han de ser citades, i la solució no es pot mantenir en secret. La llicència de Chronojump és la GNU GPL 2.0 (GNU, 1991) mentre que la de Chronopic és la Creative Commons Atribució-CompartirIgual 2.5 Es. (Creative Commons, n.d.).

El projecte Chronojump va iniciar-se com a solució per a la mesura del salt vertical a partir de plataforma de contactes. En una segona iteració s'hi van afegir nous dispositius de mesura com ara fotocèl-lules per a cronometrar la velocitat i encoders per a aportar paràmetres cinemàtics i dinàmics instantanis en exercicis d'entrenament. Les eines que s'apleguen en aquest article conformen una tercera iteració en què el programari i el maquinari arriben a professionals d'altres àmbits i necessitats: gestió de dades d'entrenament en una instal-lació, mesura d'accelerometria en qualsevol població, i mesura del temps de reacció.

Les eines de Chronojump sempre han tingut el suport d'articles científics publicats pels autors d'aquestes o per altres investigadors. El dia 25 de setembre de 2016 Google Acadèmic ofereix 90 resultats amb la paraula Chronojump. La revista Aloma ja va publicar un article de Chronojump l'any 2005 (De Blas, 2005).

\section{Part 1: Disseny i implementació d'un entorn centralitzat vinculat al projecte lliure Chronojump}

La indústria del fitnes és una de les que més han crescut en els últims temps (Malley, 2014). Thompson (2013) identifica les noves tendències del fitnes (taula 1), preveu un futur creixent en el món del fitnes, i recalca el fet que dins d'aquest sector contempli l'ús de les noves tecnologies i els sistemes d'informació d'una manera generalitzada. En la mateixa taula s'observa que en primera i en quarta posició hi ha una presència explícita de l'entrenament de la força, mentre que altres de les tendències s'hi refereixen d'una manera implícita.

$\mathrm{Al}$ mercat trobem empreses que ofereixen l'avaluació de la variació de la posició, la velocitat, l'acceleració, la força i la potència linealment a través d'encoders, també anomenats LPT (Linear Position Transducers), com ara Chronojump (Chronojump, Espanya), Gymaware (GymAware, Australia), Isocontrol (Isocontrol, Espanya), MuscleLab (MuscleLab, Noruega), o SmartCoach (SmartCoach, Suècia). També cal destacar encoders d'empreses que no estan orientades a l'avaluació esportiva, com són els d'Herrekor, Renishaw o WayCon (Herrekor, 2015; Renishaw, 2015; WayCon, 2015). La taula 2 ofereix una comparativa entre les ofertes de Chronojump, Gymaware, SmartCoach i Technogym. S'ha descartat MuscleLab per requerir una unitat de processament externa de preu elevat.

Els encoders detecten el moviment d'un esportista ubicat en una estació de treball concreta gràcies a un programa informàtic instal-lat en un ordinador. Aquest programa permet gestionar diferents usuaris, però, per a poder controlar una nova estació de treball, cal refer les connexions i connectar-hi un ordinador. Avui en dia els gimnasos tenen un gran nombre d'estacions de treball actives, i perquè estiguin sensoritzades (poder avaluar-ne el moviment), es requereix un ordinador en cada una, cosa que comporta un increment de cost d'equipaments i de manteniment.

Technogym destaca en la centralització de les dades amb el producte Wellness System Key, el qual incorpora un dispositiu tecnològic en forma de clau que s'assigna a un usuari. El seu ús permet a l'abonat entrar al gimnàs, obrir l'armariet, comprar als distribuïdors automàtics i també, si ho associa a cadascuna de les màquines on s'exercita, enregistrar la informació per possibilitar-li un seguiment del seu pla d'entrenament. Segons Technogym, el dispositiu ofereix al propietari del local esportiu un detall complet de l'ús dels equips i li permet identificar els usuaris amb risc de donar-se de baixa. De cara a l'usuari, serveix, a més, com a element motivacional per a seguir el seu pla d'entrenament (Technogym, 2014). Duarte (2010) identifica com a desavantatges les pauses que provoca en l'entrenament per la saturació del sistema en si mateix, i l'elevat

Taula 1. Top 20 de noves tendències del fitnes

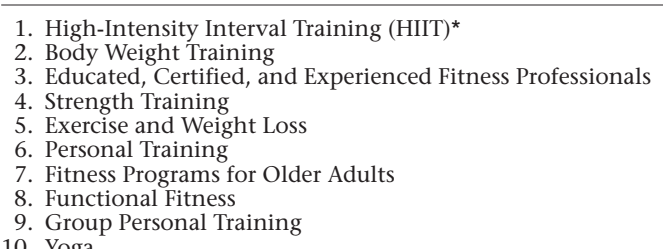

11. Children and Exercise for the Treatment/Prevention of Obesity

12. Worksite Health Promotion

13. Core Training

14. Outdoor Activities

15. Circuit Training

16. Outcome Measurements

17. Wellness Coaching

18. Sport-Specific Training*

19. Worker Incentive Programs

20. Boot Camps 
Taula 2. Comparativa entre Chronojump, Gymaware, Smartcoach i Technogym

\begin{tabular}{|c|c|c|c|c|}
\hline & Chronojump & Gymaware & Smartcoach & Technogym \\
\hline $\begin{array}{l}\text { Programari d'ordinador per } \\
\text { a l'anàlisi de força i potència }\end{array}$ & Chronojump & Power \& Strength Analysis) & Smartcoach & No \\
\hline $\begin{array}{l}\text { Necessitat de llicència } \\
\text { de pagament del programari }\end{array}$ & No & Sí & Sí & - \\
\hline Tests de salts & Sí & Jump Testing & No & No \\
\hline Interacció social & No & LeaderBoard & No & No \\
\hline Xarxa per a centralitzar dades & No & Gymaware Cloud & Smartcoach Pro & Mywellness cloud \\
\hline Encoder & Sí & Gymaware PowerTool & Smartcoach Power Encoder & $\begin{array}{l}\text { Sí (integrat en algunes } \\
\text { màquines) }\end{array}$ \\
\hline Màquines inercials & Sí & No & Sí & $\begin{array}{l}\text { Sí (integrat en algunes } \\
\text { màquines) }\end{array}$ \\
\hline Fotocèl-lules & Sí & No & No & No \\
\hline Acceleròmetres i giròscops & No & No & No & No \\
\hline Servei d'Entrenament & No & No & Entrenament a distància & $\begin{array}{l}\text { Mywellness Coach Soultion / } \\
\text { My Trainer }\end{array}$ \\
\hline Formació & Cursos de formació & No & Cursos de formació & $\begin{array}{l}\text { Technogym Education, } \\
\text { i Wellness Institute }\end{array}$ \\
\hline Solucions financeres & No & No & No & Sí \\
\hline Disseny d'espais adaptat & No & No & No & Sí \\
\hline Disseny de màquines particulars & No & No & No & Sí \\
\hline Programari i Maquinari lliures & Sí & No & No & No \\
\hline
\end{tabular}

Font: Elaboració pròpia.

cost de la infraestructura.

El present treball pretén utilitzar ordinadors de baix cost connectats entre ells per cada estació de treball per tal de fer-ne una recopilació de dades de manera automàtica i centralitzada. Aquests ordinadors executaran el programari Chronojump. L'estat actual d'aquesta solució lliure i la capacitat de fer-hi adaptacions el fan ideal per al propòsit perseguit.

Els objectius es divideixen en dues parts:

1. Desenvolupament del Sistema:

1. Dissenyar un sistema centralitzat per a l'anàlisi de l'entrenament de la força i la potència mitjançant Chronojump.

2. Identificar miniordinadors que puguin adaptar-se a Chronojump.

3. Possibilitar als usuaris el control remot del programa.

4. Possibilitar el fet d'identificar-se mitjançant radiofreqüència.

2. Tests del Sistema:

1. Identificar el miniordinador que executa les tasques específiques en menor temps.

2. Identificar el miniordinador més eficient quant a la temperatura del sistema.

\section{Metodologia}

Per tal de desenvolupar el sistema, s'ha fet una revisió i una valoració en clau d'inclusió o descart de quatre àrees tecnològiques vinculades als objectius de desenvolupament.

D1) Linux, Samba i Màquines virtuals

D2) Microprocessadors: Arduino; i miniordinadors: RiKomagic, Raspberry Pi i Banana Pi

D3) Control remot via WiFi

D4) Identificació per radiofreqüència
El procés metodològic per a incloure o excloure les tecnologies citades s'il-lustra en la figura 1. Per cada àrea tecnològica es va fer una recerca de documentació inicial que posteriorment era revisada per experts en la matèria. Posteriorment s'adquirien els recursos necessaris (ja sigui a nivell de maquinari o de programari) per a la posada en funcionament i avaluació. Arribats a aquest punt, es consideraven tres alternatives: la necessitat d'una nova revisió de la tecnologia (es tornaria a començar el procés metodològic descrit), l'exclusió d'aquesta, o bé la seva inclusió. En cas que la tecnologia fos acceptada i que no hi hagués cap guia específica d'ús, s'elaboraria una guia.

Per tal de realitzar els tests del sistema es van registrar les variables temps i temperatura utilitzant el programa informàtic Chronojump (equipat amb un Chronopic i un encoder), una càmera d'alta velocitat Casio model Ex ZH 100 a 120 imatges per segon, un cronòmetre, el programa informàtic Kinovea per a poder extreure'n els resultats temporals precisos i el reproductor de vídeo VLC. A més, durant el procés de

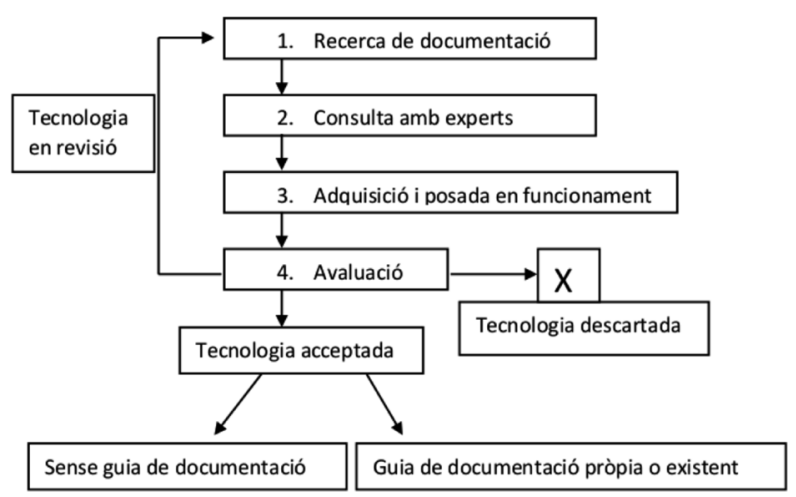

Figura 1. Procés metodològic del Desenvolupament del Sistema. Font: Elaboració pròpia. 
les proves s'executaven dos programes per a controlar el consum de recursos: el programa top, i la temperatura: cat /sys/class/thermal/thermal_zone0/temp (a la Raspberry Pi), i cat/sys/devices/platform/sunxi-i2c.0/ i2c-0/0-0034/temp1_input (a la Banana Pi).

Es van realitzar, diversos cops, cinc tests de rendiment modificant la velocitat del rellotge. Inicialment amb les velocitats que els miniordinadors utilitzen per defecte de fàbrica (700 Mhz) i, per veure'n la seva potencialitat, es va incrementar primer a freqüències d'una potència intermèdia (900 Mhz), i finalment a una de màxima (1 Ghz). Les quatre primeres proves tenien com a variable el temps i la cinquena considerava la temperatura:

T1) Temps que triga a obrir el programa Chronojump. Comptant des que se selecciona per obrir el programa fins que aquest està disponible per a poder-hi treballar.

T2) Temps necessari entre la finalització de la sèrie i la visualització de la totalitat de les dades de l'exercici. La referència temporal inicial va ser quan es pitjava el botó de «fi», i la final quan apareixien els resultats de la simulació de 5 moviments d'aixecament de banca. Per tal d'unificar un criteri per a tots els dispositius i freqüències de rellotge es van realitzar 4 captures, i en cadascuna s'hi feien 5 moviments.

T3) Temps que necessita el dispositiu des que se selecciona l'opció de tornar a carregar els valors d'una sèrie i el seu visionament. La sèrie seleccionada sempre va ser la mateixa execució d'aixecament de banca de 5 moviments, en el quals es va trigar 4 segons des que es va pitjar el botó de captura fins a l'inici del moviment.

T4) Temps que necessita el dispositiu des que se selecciona l'anàlisi de 'comparar lateralment' i la seva visualització. La referència temporal inicial va ser el moment de pitjar el botó d'analitzar, i la final quan es visualitzava la informació per pantalla. L'anàlisi sempre es va realitzar amb una simulació d'aixecament de banca d'una sèrie d'11 moviments excèntrics/concèntrics.

T5) Temperatura del processador durant la reproducció d'un vídeo. El vídeo escollit ocupava $110 \mathrm{MB}$ i durava 2 minuts i 40 segons.

\section{Resultats i discussió}

Quant al desenvolupament del sistema, aquests són els resultats del procés metodològic per a cada una de les àrees tecnològiques:

D1) Linux, Samba i Màquines virtuals. Després de realitzar proves amb Samba i Active Directori mitjançant una màquina virtual (VirtualBox), i configurant un entorn de gestió d'usuaris, es va decidir descartar aquestes tecnologies en pro de la creació d'un servidor propi de Chronojump que reduirà la complexitat d'integració en la codificació del programa client. El programa servidor s'ha iniciat, però encara no està completat.
D2) Microprocessador: Arduino; i miniordinadors: RiKomagic, Raspberry Pi i Banana Pi. Arduino es va descartar quan es va veure que era millor que el dispositiu inclogués el programa Chronojump complet, i un microprocessador no permet executar tota la solució. RiKomagic es va descartar pel fet d'estar massa orientat a l'entorn multimèdia. Tant Raspberry Pi com Banana Pi poden servir per a dur a terme aquesta funció un cop resolts els problemes de compilació del programari. La tria d'una o altra dependrà de la relació potència/preu en els pròxims anys i de la possible aparició d'alternatives compatibles que siguin massivament adoptades. S'ha elaborat una guia de compilació per a aquestes plataformes.

D3) Control remot via WiFi. S'ha acceptat i redactat una guia per a la configuració de dispositius d'escriptori remot basats en RDP, com AfreeRDP i aRDP.

D4) Identificació per radiofreqüència. Després de diverses proves s'ha acceptat el lector de NFC (comunicació de camp proper) NC522 en detriment del model PN532. Es va adaptar el programari Chronojump per a llegir en NC522 i autenticar l'usuari a partir d'una base de dades local. Finalment es va redactar una guia per a la seva configuració i ús.

Quant als tests del sistema, la figura 2 mostra que el temps que triguen a executar-se les diferents operacions són més baixos i, en general, més estables en la Banana Pi, a excepció del temps d'anàlisi de la sèrie. El temps necessari per a mostrar les dades després de la captura és, sens dubte, el que cal treballar més a nivell de programari i configuració de les màquines perquè 5-10 segons dificulta la seva usabilitat.

Quant a la temperatura del processador durant la reproducció d'un vídeo, els resultats (vegeu figura 3)

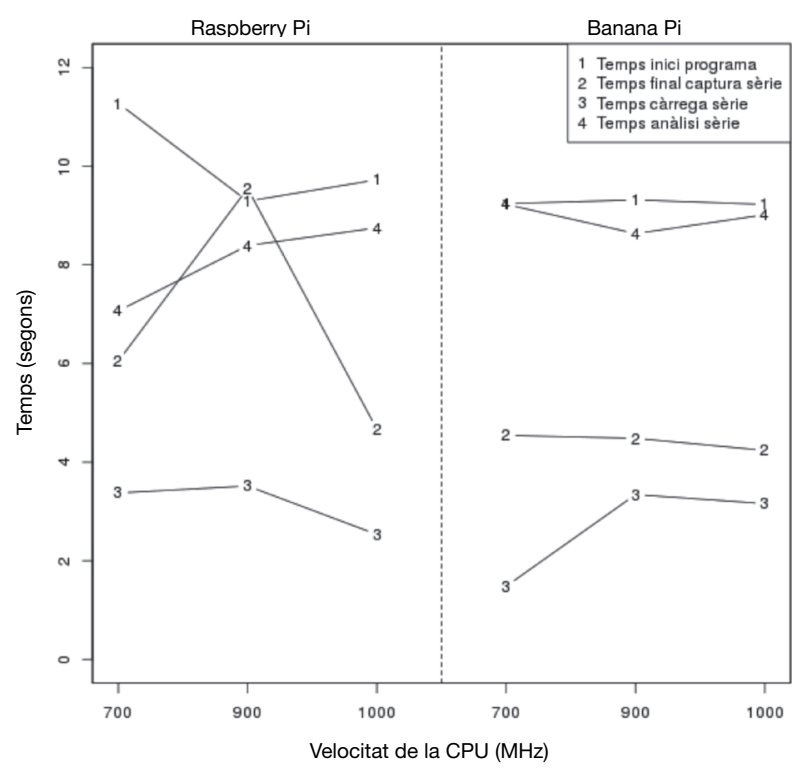

Figura 2. Temps mesurat en cadascun dels tests: T1) temps en arrancar el programa; T2) temps entre la fi de l'execució de I'exercici i la visualització dels resultats; T3) temps en carregar una sèrie; T4) temps que triga a analitzar una sèrie. 


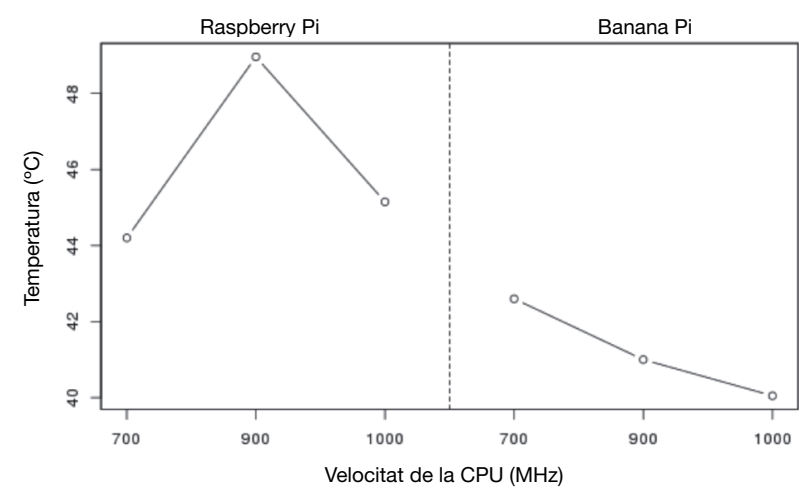

Figura 3. Temperatura del processador en ${ }^{\circ} \mathrm{C}$.

reflecteixen que la reproducció del vídeo amb la Banana Pi produeix una temperatura menor en el processador per a totes les seves velocitats de rellotge.

Del test del sistema se n'extreu que el dispositiu Raspberry Pi obté uns resultats força semblants als de la Banana Pi. Quant a la temperatura, tot i que la Raspberry Pi ha arribat a valors més alts, aquests no es consideren alarmants. La major comunitat de la Raspberry Pi fa que sigui l'opció preferida davant la no-superioritat de la Banana Pi quant a rendiment.

\section{Part 2: Anàlisi de moviments no lineals} amb accelerometria usant quaternions

\section{Introducció}

El desenvolupament tecnològic ha permès l'aparició de dispositius fàcils d'utilitzar que valoren el nivell d'activitat física de manera objectiva (Santos i Garatachea, 2012); un exemple d'aquests instruments són els monitors de freqüència cardíaca, que van aparèixer en la dècada dels 90 del segle xx i que van esdevenir el mètode preferit de molts investigadors per a mesurar la intensitat de l'exercici físic mitjançant les pulsacions per minut. Més endavant, s'utilitzaren els podòmetres per a mesurar el grau d'exercici físic mitjançant la mesura objectiva del nombre de passes al dia, però amb l'inconvenient que no podien quantificar la intensitat. Per aquest motiu, en els darrers anys ha augmentat l'ús d'altres eines objectives per a la quantificació d'aquest exercici físic: els acceleròmetres.

Durant els anys 90, l'accelerometria encara es trobava en fase de desenvolupament, i no va ser fins a l'any 1999 que en el congrés Measurement of Physical Activity, a l'Institut Cooper, es van atorgar eines, conclusions i recomanacions futures respecte a l'accelerometria a la comunitat científica; i des d'aquell moment, s'han millorat els avenços tecnològics en aquest camp d'investigació (Santos i Garatachea, 2012). Els mateixos autors adverteixen que, tot i que els acceleròmetres són útils per a mesurar els nivells d'exercici físic i estimar una despesa energètica, tenen algunes limitacions, com ara aquestes: el fet que cada marca de dispositius inclogui el seu propi programari, necessari per a iniciar, configurar i descarregar el registre de cada dispositiu; un temps llarg a l'hora de processar i analitzar les dades obtingudes; l'entrenament dels usuaris per tal que utilitzin correctament el dispositiu i cuidin la localització d'aquest en el cos; el seguiment d'un protocol previ de configuració del dispositiu, o l'elevat preu que tenen aquests dispositius.

Intille, Lester, Sallis, i Duncan, (2012) arriben a la conclusió que aquests dispositius d'accelerometria han de ser dissenyats de manera que siguin portàtils, compactes i sense cap cable o amb la menor quantitat possible, i la capacitat de processament de dades i emmagatzematge d'aquestes s'ha de poder dur a terme en un període extensiu de temps. A més, també han de ser petits i fàcils de portar perquè els usuaris puguin dur més d'un sensor en les diferents parts del cos o a la roba, còmodament.

Tot i que l'accelerometria proporciona directament l'acceleració com a resultant, en la majoria d'ocasions aquest no és el paràmetre que interessa, sinó que cal realitzar una sèrie d'operacions per a aconseguir el paràmetre desitjat. Per exemple: a partir de l'acceleració i la massa s'obté la força exercida, i a partir de la integració de l'acceleració s'obté la velocitat. Multiplicant-les totes dues s'aconsegueix la potència. Les fórmules amb les quals es treballa per obtenir aquest tipus de dades, són bàsicament les següents:

- Força $(\mathrm{N})=\mathrm{m} \cdot \mathrm{g}+\mathrm{m} \cdot \mathrm{a}(\mathrm{a}=$ Acceleració, $\mathrm{g}=$ Gravetat).

- Velocitat $(\mathrm{m} / \mathrm{s})=$ Integral de l'acceleració.

- $\quad$ Espai $(\mathrm{m})=$ Integral de la velocitat.

- Potència $(W)=$ Força $\cdot$ Velocitat.

Segons De Blas (pàg. 36, 2012), hi ha dos problemes que acostumen a apareixen en l'ús dels acceleròmetres: la dificultat per a obtenir l'espai recorregut d'una manera precisa i la dificultat de determinar l'inici i el final del moviment. En el primer cas és degut al fet que cal realitzar una doble integració, operació que comporta un error considerable i ha de ser corregida amb complexos algoritmes de filtració. En el segon cas, l'acceleròmetre té moltes dificultats per a advertir l'inici i el final del moviment pel fet que sempre està detectant moviments per petits que siguin, i això obliga a l'executant a estar molt quiet a l'inici, cosa que no sempre es pot aconseguir.

Existeixen dos tipus de dispositius per a l'avaluació del moviment a partir de l'accelerometria: els que utilitzen instrumentació pròpia i els que utilitzen un telèfon tipus smartphone. Els primers inclouen més funcionalitats i les seves mesures són suposadament més fiables; els segons tenen l'avantatge de ser força més barats. Entre els que utilitzen instrumentació pròpia destaquem els següents: Achillex Jump'n'Run (Humotion, Alemanya), Beast Sensor (Beast Technologies, Itàlia), FreePower (Sensorize, Itàlia), Gymwatch (Gymwatch, USA), Keimove (Vincid, Espanya), Myotest (Myotest, Suïssa), VertiMetric (Lafayette, USA) i Wimu (RealTrack Systems, Espanya). Entre els segons, és a dir, entre els que utilitzen.les aplicacions per a smartphone, destaquem Gravitometer, iSeismometer i el Liza Plus. 
Tot i que la validesa d'alguns dels sistemes ha estat demostrada (Casartelli, Müller i Maffiuletti, 2010; Picerno, Camomilla i Capranica, 2011), els resultats que s'obtenen a partir dels diferents dispositius són força diferents i, com que no són programari lliure, no es pot veure quin algoritme segueixen i, per tant, saber si els càlculs estan ben fets o no.

L'única eina tecnològica per a la detecció de paràmetres esportius de curta durada i que està sota llicència lliure és Chronojump. Els seus autors estan treballant en un dispositiu lliure que integra acceleròmetre, giroscopi i magnetòmetre. El problema rau en en el fet que encara no usa quaternions per a realitzar els càlculs, mancança que provoca que els eixos de referència a l'inici són ortogonals però al llarg del moviment els eixos es van aproximant i les acceleracions que es calculen no es corresponen amb la realitat.

Els quaternions es fonamenten en el sistema de Nombres Complexos. A part de contenir tots els nombres pertanyents als conjunts de Nombres Naturals, Enters, Reals i Racionals, els Nombres Complexos es caracteritzen pel fet d'introduir un nou sistema de nombres que van ser inventats per tal de resoldre equacions sense solució, com per exemple $x^{2}=-1$. D'aquesta manera, els nombres complexos estan caracteritzats per a tenir una component imaginària, $i$, que equival a la arrel quadrada de $-1(\sqrt{-1})$. Així doncs, el conjunt de nombres complexos es poden expressar de la següent manera:

$$
z=a+b \cdot i, \text { on } a, b \in R, \mathrm{i} i^{2}=-1 .
$$

Tècnicament, els quaternions són 4 nombres: una part real i tres imaginàries, de manera que $i=j=k=$ $\sqrt{-1}$, i $i^{2}=j^{2}=k^{2}=i j k=-1$. Així, podem definir els quaternions segons l'expressió següent:

$$
\begin{gathered}
q=w+x \cdot i+y \cdot j+z \cdot k, \text { on } w, x, y \text { i } z \text { són nombres } \\
\text { reals }(w, x, y, z \in R) .
\end{gathered}
$$

D'aquesta manera, els quaternions permeten estendre el conjunt de nombres Complexos en un espai tridimensional afegint dues components imaginàries. Aquests, tenen unes components $x, y$ i $z$ de l'espai que representen un eix a on hi haurà una rotació, i una component $w$ que indica la rotació total que hi haurà sobre aquest eix definit. Per tant, un quaternió és un vector de 4 elements que es pot utilitzar per a codificar qualsevol rotació en un sistema de coordenades de 3 dimensions; és a dir, són una eina molt útil per a representar rotacions a l'espai. Quant a la programació matemàtica i estadística, en els darrers anys el llenguatge de programació R està essent més usat en la publicació científica. Segons Fox i Andersen (2005), R és un programa gratuït, lliure i desenvolupat cooperativament, que succeeix a S i S-Plus, ambdós potents i flexibles llenguatges de programació i un medi de computació estadística. Els mateixos autors qualifiquen a R com a programari de gran qualitat i funcionalitats, i d'excel-lents eines per a preparar càlculs i gràfics estadístics. També cal destacar que aquest programa funciona en els sistemes operatius més comuns del mercat, com Macintosh, Linux i Windows. Hernández i Cuevas (2013) atribueixen l'augment d'usuaris de R en els darrers anys a la permissibilitat d'estendre les seves capacitats, a través de noves funcions, a la publicació de nous «paquets» per part dels usuaris -R disposa de 8.444 paquets lliures el maig del 2016 (CRAN, 2016)- i a la creació d'interfícies gràfiques que faciliten la interacció de l'usuari amb R. Entre aquestes interfícies gràfiques destaquen RStudio i Deducer, ambdues documentades per l'ús de càlculs estadístics (Badiella, 2015; Gandrud, 2013; R Team, 2014).

L'objectiu d'aquest estudi és utilitzar els quaternions en l'anàlisi de les dades d'accelerometria amb $\mathrm{R}$ dins l'entorn lliure Chronojump.

\section{Metodologia}

En primer lloc es va revisar tot el codi d'accelerometria existent a Chronojump per tal de modificar-lo, amb l'objectiu que usi els quaternions com a base per a la mesura. Les eines utilitzades van ser R com a llenguatge de programació, Rstudio entorn de programació, i la llibreria Onion per al tractament de quaternions.

Per a provar-lo, es va avaluar el moviment combinat que es descriu a continuació indicant les parts del moviment relatives als eixos locals de l'acceleròmetre: - A: L'acceleròmetre descansa damunt la taula durant 200 mil-lisegons. L'acceleració en l'eix Z és 9,81 per l'acció de la gravetat.

- B: L'acceleròmetre accelera 0,981 m/s² durant $100 \mathrm{~ms}$ en direcció vertical.

- C: L'acceleròmetre accelera $-0,981 \mathrm{~m} / \mathrm{s}^{2}$ durant $100 \mathrm{~ms}$ en direcció vertical.

- D: Rotació en l'eix Y de 90 graus al llarg de 200 ms.

- E: Acceleració constant de $0,981 \mathrm{~m} / \mathrm{s}^{2}$ en l'eix Z al llarg de $200 \mathrm{~ms}$.

Aquest moviment es va avaluar, en el programa en $\mathrm{R}$, de dues maneres diferents:

1) Les dades del moviment que provenia de l'acceleròmetre s'havien creat idealment (senyal molt pur). Aquest senyal està disponible a https://git.gnome. org/browse/chronojump/tree/accelerometer/ captures/0.981m.csv

2) Un subjecte movia l'acceleròmetre seguint el patró indicat anteriorment, i l'acceleròmetre captava i enviava les dades al programa en $\mathrm{R}$ perquè calculés els paràmetres cinemàtics. La dificultat d'aquesta acció rau en el fet que el moviment del subjecte afegeix molt «soroll» al senyal i necessita un calibratge dels sensors.

Com que el desenvolupament del codi es troba en una fase inicial-mitjana, no caldrà una mesura molt acurada de l'error, sinó que es compararà gràficament amb la llibreria de gràfiques 3D en temps real rgl, sempre que la trajectòria del dispositiu hagi estat calculada correctament.

\section{Resultats i discussió}

S'han escrit 233 línies de codi R en 16 funcions que estan orientades a la mesura amb quaternions. El codi 


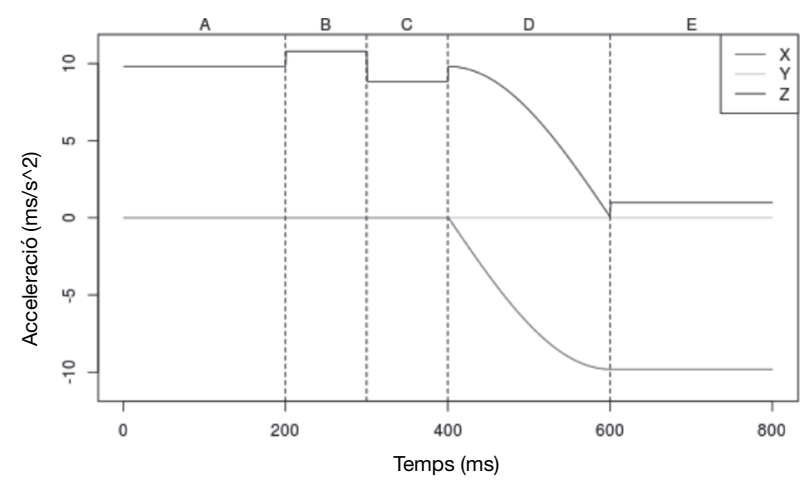

Figura 4. Acceleracions 3D relatives al llarg del temps.

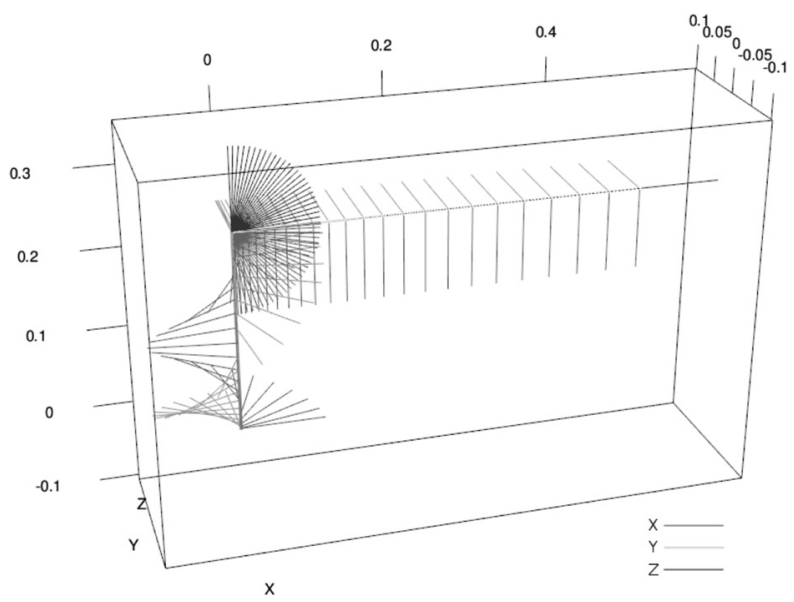

Figura 5. Relació entre l'espai desplaçat i els eixos locals de l'acceleròmetre.

està disponible a https://git.gnome.org/browse/chronojump/tree/accelerometer/accelerometria.R

La prova del senyal pur mostra com les dades calculades corresponen a les dades inicials, mentre que en la prova amb el moviment humà apareix un error important que obliga a continuar amb el calibratge i la correcció de soroll del senyal.

La figura 4 mostra, en cada una de les fases, la correcta interpretació de les dades per part de l'acceleròmetre en el senyal pur. En la figura 5 es veu que la relació entre l'espai desplaçat i els eixos locals de l'acceleròmetre es correspon amb el senyal pur creat.

Per tant, com a resultat de l'estudi, s'aconsegueix llegir correctament un senyal ideal pur, però es constata que cal millorar el calibratge i la correcció del senyal provinent del moviment humà (impur).

\section{Part 3: Disseny d'instruments per a mesurar el temps de reacció: Temps de reacció electiu, mesura de l'anticipació i flicker}

\section{Introducció}

La mesura del temps de reacció s'ha denominat també velocitat de reacció i temps de latència. Per exemple, Woodworth i Scholosberg (1954) parlen inicialment de temps de reacció, però posteriorment passen a denominar-ho latència de resposta, concepte que defineixen com l'interval de temps existent entre l'estímul i la resposta. Henry i Rogers (1960) el defineixen com el període latent entre l'estímul i el primer començament del moviment físic. Amb aquestes fonts s'aprecia una certa uniformitat en el fet de determinar que el començament del mesurament es troba a l'inici de l'estímul i el final a l'inici de la resposta a aquest.

Roca (1983) utilitza el concepte velocitat de reacció com a sinònim de temps de reacció, i, a més, diferencia entre temps de reacció simple i electiva. Beisey i Peaseley (1937) es refereixen a la velocitat de reacció com una qualitat física el mesurament de la qual es realitza mitjançant el temps de reacció. Segons Roca (1983), altres autors utilitzen expressions com aquestes: velocitat de reacció motora (Frey), temps de reacció (Verjoshanski, Kostial), velocitat de reacció simple $i$ complexa (Matveiev), temps de latència de la reacció motora (Sergienko), reacció motora general (Füchs), temps de reacció motora (Baranov, Tabashnik), capacitat de reacció de sortida (Podlivaev), velocitat de reacció (Bauersfeld) i especialització de reacció motora (Drizka).

Nakamura (1934) anomena temps de reacció simple l'executat amb les mans, i el distingeix del temps de reacció corporal. que és el realitzat amb tot el cos. Una segona classificació és la determinada pel criteri sensorial de percepció de l'estímul, podent ser aquest visual, auditiu, tàctil i cinestèsic. Altres classificacions estan determinades en funció del nombre d'alternatives o associacions estímul-resposta, com les desenvolupades per Woodworth i Scholosberg (1954), els quals anomenen reacció simple aquella que té un estímul uniforme i provoca una resposta també uniforme, i reacció complexa aquella en la qual hi ha una reacció disjuntiva o d'elecció en què es presenten diferents estímuls que puguin demanar diferents respostes. Schmidt (1991) defineix temps de reacció electiva com l'interval més curt necessari per a respondre a un estímul, que es presenta com una alternativa davant diversos estímuls.

Un concepte pròxim al de temps de reacció és el d'anticipació. En una mesura d'anticipació, l'avaluat observa una seqüència de llums i ha d'encertar en quin moment s'encendrà un llum determinat. Els dispositius d'anticipació poden funcionar a diferents velocitats seleccionables per l'avaluador. Segons Poulton (1957), citat per Schmidt i Lee (2011), hi ha tres tipus diferents d'anticipació. Un d'aquests tipus és el receptor anticipation, en el qual el subjecte detecta les coses pròximes de l'entorn amb diferents receptors sensorials. Aquest mateix subjecte ha d'estimar el temps que trigarà a fer el seu moviment per a calcular l'interval fins que comenci l'acció. D'això se'n diu effector anticipation perquè la durada del moviment que es fa ha de ser predita. Per últim, Poulton va descriure l'últim tipus com a perceptual anticipation, en el qual les coses de l'entorn no són percebudes directament, però encara són predictibles, ja que, el subjecte ha tingut una gran quantitat de pràctica amb aquestes coses. Segons Schmidt i Lee (2011), l'anticipació és una estratègia per a reduir el temps o, fins i tot, les etapes de processament que normalment estarien involucrades en la resposta a un estímul inesperat. 
Un dispositiu que usa tecnologies similars a les utilitzades per la mesura del temps de reacció és l'anomenat flicker. Aquest conté un led a l'interior d'una capsa tancada i un polsador. La capsa té dos forats a manera de prismàtics per a poder veure el led de dins. La fatiga es mesura mitjançant la percepció de la intermitència del led. L'avaluat mira pels forats i observa el led que hi ha encès a una freqüència determinada, el qual va disminuint progressivament; quan l'usuari comenci a percebre la intermitència en el led, pitjarà el polsador. És molt difícil trobar bibliografia relativa als flickers, ja que que eren usats principalment a l'antiga URSS i no se'n troben publicacions. Segons J. M. Padullés (comunicació personal, 26 de febrer, 2015), la utilitat principal dels flickers va ser quantificar l'entrenament en funció de la fatiga detectada a l'inici d'aquest. En l'àmbit estatal existeixen aplicacions del flicker en les ciències de l'esport per part de Cruz i García (1991), i Solé, Quevedo, Augué, i Morales (2004).

Les eines tecnològiques per a mesurar el temps de reacció que es troben al mercat són d'elevat cost, no són lliures, i no acostumen a integrar temps de reacció electiu, anticipació i flicker. Per altra banda, el projecte Chronojump és una solució tecnològica lliure que incorpora mesura del temps de reacció però que requereix que l'estímul sigui iniciat per un avaluador extern, i tampoc no integra flicker, ni anticipació ni temps de reacció electiu.

Els objectius són els següents:

1. Elaborar una placa genèrica per a la mesura del temps de reacció.

2. Elaborar dispositius que interaccionaran amb l'usuari per a la mesura del temps de reacció electiu, anticipació i flicker.

3. Adaptar el firmware de Chronopic per a la funcionalitat d'aquesta placa.

4. Adaptar el programari Chronojump per a usar les noves funcions, com també iniciar un estímul aleatòriament.

5. Comparar els temps de reacció per estímul visual, auditiu i electiu en una mostra.

\section{Metodologia}

Per al primer objectiu, «Elaborar una placa genèrica per a la mesura del temps de reacció», es va dissenyar una placa amb el programari lliure KiCad i posteriorment es va muntar en una placa Topos manualment per tal de determinar si hi havia alguna errada en el disseny.

La placa genèrica de temps de reacció fa de pont entre la placa Chronopic i els dispositius perifèrics. La placa Chronopic conté un microcontrolador Pic que és l'encarregat d'analitzar totes les dades i canvis exteriors que li arriben, i enviar la informació processada a diferents senyals de sortida. Per a dissenyar la placa de temps de reacció s'utilitzen 5 senyals de sortida del Chronopic que queden lliures, els quals, juntament amb l'alimentació, van a parar al port Ethernet, on s'aprofita per poder fer la connexió a la placa de temps de reacció i es procura que, a l'usuari, li sigui més fàcil la connexió.
Dels 5 senyals que Chronopic envia a la placa de temps de reacció, 4 les desmultiplexa en 16 senyals, mentre que el senyal que queda va directe sense desmultiplexar. En total la placa converteix 5 senyals en 17 senyals, que permeten disposar de 17 estímuls a conveniència. A part de contenir aquests senyals, la placa fa de barrera entre dues tensions diferents. El Chronopic va alimentat a través de l'USB de l'ordinador; per tant, utilitza $5 \mathrm{~V}$, a diferència dels dispositius perifèrics, que van alimentats a $12 \mathrm{~V}$. Aquesta diferència de voltatge és bàsicament per poder tenir components més potents connectats; per exemple, leds d'alta lluminositat, alguna bombeta de $12 \mathrm{~V}$ o alguna sirena o buzzer. Per aquest motiu, la placa de temps de reacció fa de barrera separant el voltatge que ve dels senyals del Chronopic amb els senyals desmultiplexats que envia als altres dispositius. Aquesta separació dels voltatges s'aconsegueix amb un circuit integrat que conté un array de transistors per als 16 senyals desmultiplexats i amb un fotoacoblador per al senyal individual. L'alimentació de $12 \mathrm{~V}$ necessaris per als dispositius perifèrics està inclosa en la placa de temps de reacció, tenint-ho, així, tot compacte en una sola placa.

Els components de la placa són: ULN2803 (x2), 74HC4514, RJ45, H11A1, JACK alimentació, Resistència, Connectors 8pins (x2) i Connector 2pins. El programa KiCad permet el disseny esquemàtic, indicant on va connectat cada component, i el disseny Layout, que serveix per a minimitzar l'espai final de la placa.

Per al segon objectiu, «Elaborar dispositius que interaccionaran amb l'usuari per la mesura de temps de reacció electiu, anticipació i flicker», es van elaborar circuits d'entrada / sortida amb leds, buzzers i polsadors.

El dispositiu per a la mesura del temps de reacció electiu es dissenyarà amb tres leds de diferents colors i un buzzer, de manera que permeti mesurar el temps de reacció electiu i comparar el temps de reacció entre un estímul auditiu i un de sonor. L'avaluador podrà especificar quin estímul és el rellevant, i l'usuari tindrà el polsador preparat per a quan vegi o escolti l'estímul que s'havia acordat.

El mesurador d'anticipació es va dissenyar amb 15 leds en disposició circular -tot i que en un futur l'usuari podrà canviar-ho-, activats per 15 senyals de la placa. Els leds s'encenen de manera successiva fent l'animació circular, essent el temps que transcorre d'un led al següent una variable coneguda que permetrà saber a quina velocitat s'executa la prova. L'avaluador escollirà el temps de rotació dels leds i indicarà quin és el led en què s'ha d'aturar la prova. Llavors l'avaluat té un polsador que l'haurà de polsar quan el led indicat s'encengui.

El flicker tindrà un led a l'interior d'una capsa tancada. Aquesta capsa té dos forats, com si fossin uns prismàtics, per a poder veure el led de dins. L'usuari observarà el led que estarà encès a una freqüència determinada, la qual anirà reduint-se progressivament fins que l'usuari percebi la intermitència en el led i pitgi el polsador.

Per al tercer objectiu, «Adaptar el firmware de Chronopic per a la funcionalitat d'aquesta placa», es va re- 
faccionar el firmware per tal d'afegir les noves funcionalitats i es van corregir els diferents timers per a les freqüències desitjades. El firmware del Chronopic és tot el programa que fa que els components electrònics (maquinari) mesurin o realitzin coses. Aquest programa té un codi escrit en llenguatge de programació C, que és el més popular per a crear programari de sistemes. Es van realitzar funcions específiques per a cadascuna de les aplicacions: temps de reacció electiu, anticipació i flicker. També es van crear i combinar amb el programa els punts d'entrada per a les variables del firmware. La freqüència de canvi de llums en el dispositiu d'anticipació s'ha ajustat amb 8 valors possibles entre 15.625 mil-lisegons i 2 segons. Per a saber si aquestes freqüències de canvi de llums són acurades, es van filmar, amb la càmera Casio ZR1000, 1000 imatges per segon, i es van ajustar els timers a conveniència.

Quant al quart objectiu, «Adaptar el programari Chronojump per a usar les noves funcions, com també iniciar un estímul aleatòriament», es van programar en C\# les diferents classes (mecanismes de definició d'objectes de programari) i mètodes (funcionalitats d'aquests) per tal de tenir una gestió adient d'un model de dades, una interfície moderna i uns controladors que vinculin el model i la interfície en la línia del conegut paradigma: model, vista, controlador. Un cop programat, es va realitzar una bateria de proves per a veure si hi havia errades que impedissin el funcionament del programa o que (encara més greu) mostressin resultats erronis.

Finalment, per al cinquè objectiu, «Comparar els temps de reacció per estímul visual, auditiu, i electiu en una mostra», es va triar una mostra de 10 alumnes de CAFE de Blanquerna de $4^{\mathrm{t}}$ curs $24.1 \pm 1.0$ anys (tots nois). Cada subjecte va realitzar 10 temps de reacció visuals, després 10 d'auditius I, finalment, 10 d'electius. Els electius tenien tres opcions: s'activa la llum verda (estímul positiu), s'activen simultàniament les llums verda i vermella (estímul negatiu), i s'activen simultà-

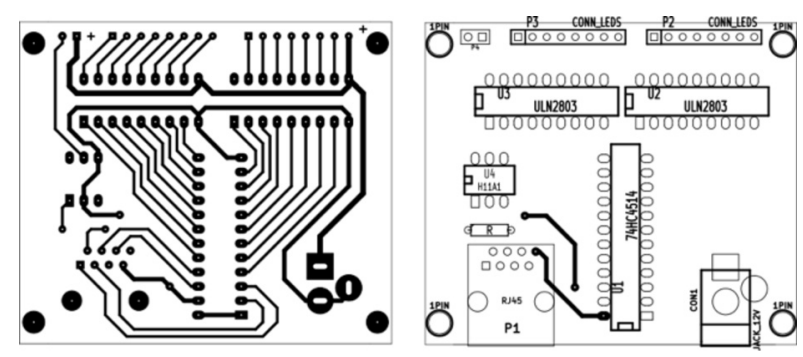

Figura 6. Layout de la placa elaborat amb el KiCad.

niament la llum verda i el buzzer (estímul negatiu). Es va generar una seqüència aleatòria per a cada subjecte, en què l'estímul positiu tenia una probabilitat de 4/6, mentre que cada estímul negatiu tenia una probabilitat d'1/6. L'usuari havia de pitjar un polsador només quan s'activava l'estímul positiu. L'estímul s'activava pel microcontrolador passat un període aleatori entre 1 i 3 segons des que l'avaluador seleccionava el tipus d'estímul a l'ordinador. Es van cercar diferències significatives amb el programa R 3.1.1 usant T Student i ANOVA en les agrupacions de 2 i 3 nivells de factors, respectivament.

\section{Resultats i discussió}

La placa de maquinari i els dispositius han estat creats de forma no industrial, tal com es pot veure en les figures 6,7 i 8 .

El codi font afegit al firmware ha comportat 240 línies de codi en C. Es pot consultar el codi íntegre en https://git.gnome.org/browse/chronojump/tree/chronopic-firmware/chronopic-firmware-c/chronopicfirmware-multitest.c

L'errada observada en el dispositiu d'anticipació és de $0,025 \%$ quan va a la màxima velocitat (canvi de llum cada 15.625 mil-lisegons), i de 0,031\% quan el canvi es produeix cada segon. En el primer cas aquesta
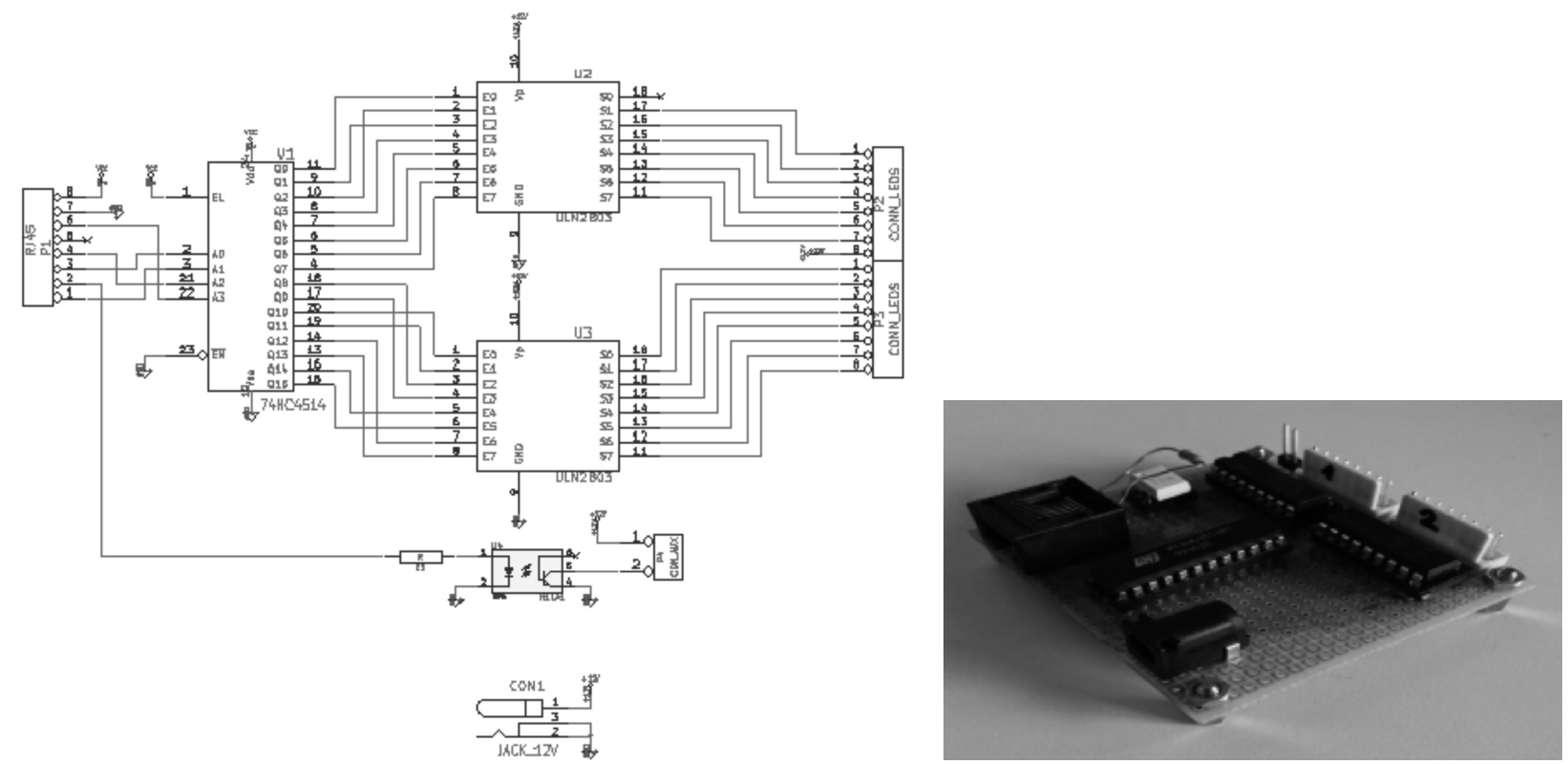

Figura 7. Disseny esquemàtic de la placa, i placa construïda de forma manual (Topos). 

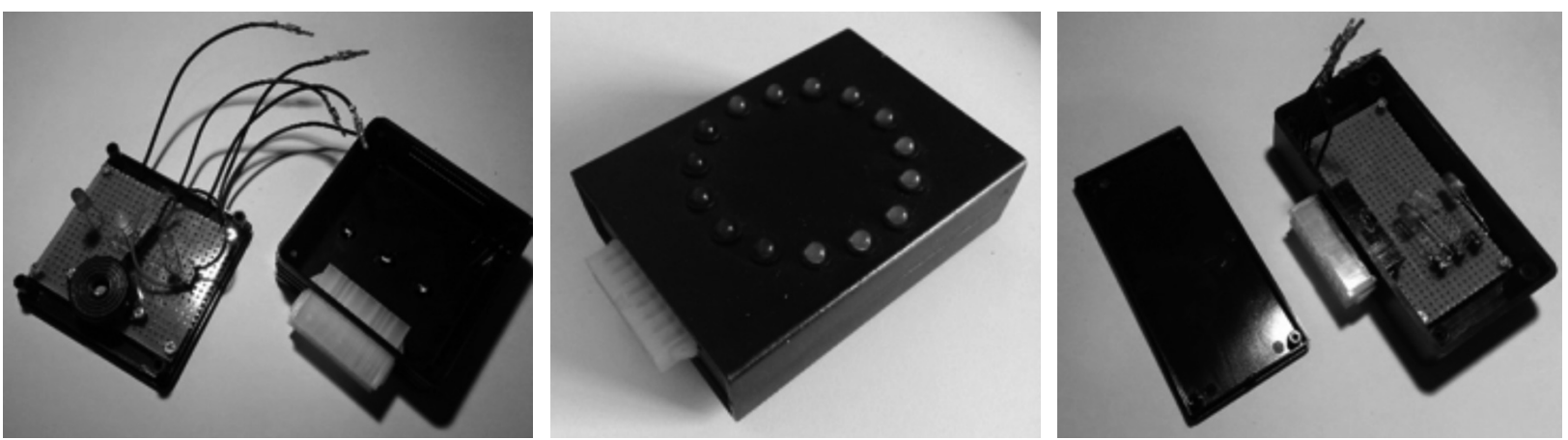

Figura 8. Perifèrics creats per al temps de reacció electiu, anticipació i flicker.

Chronojump - Demo temps reacció

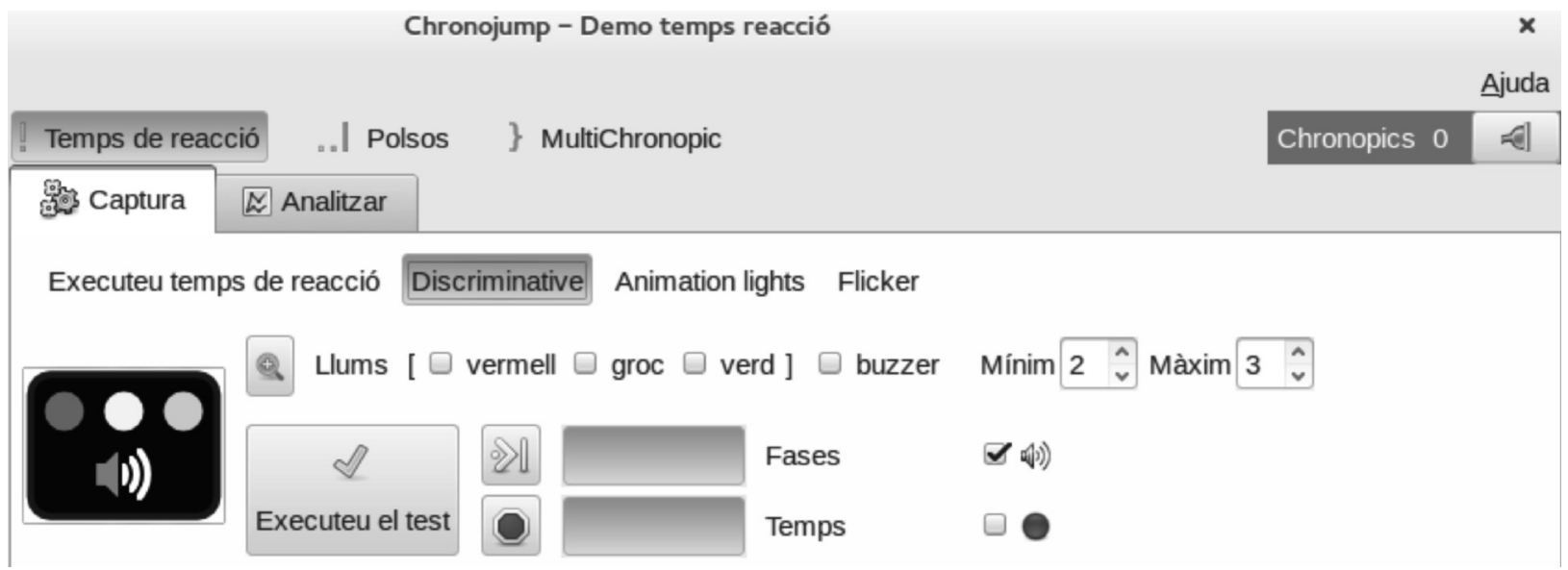

Figura 9. Interfície gràfica de Chronojump per al temps de reacció electiu.

errada es tradueix en el fet que els 15.625 mil-lisegons de canvi són, en realitat, 15.562 mil-lisegons, mentre que, en el segon cas, els 1000 mil·lisegons són 1001.812. En ambdós casos es tracta d'una errada sistèmatica, estable i menyspreable. De tota manera, encara hi ha marge per a reduir aquests valors en cas que es volgués ajustar millor el temps.

Quant al programari Chronojump, les funcions relatives al fet que s'enviï el senyal al Chronopic s'han acabat i han suposat un total de 104 línies de C\#. Es pot consultar el codi íntegre en https://git.gnome.org/ browse/chronojump/tree/src/gui/reactionTime.cs

La interfície gràfica per a iniciar l'estímul, gestió de resultats i presentació a l'usuari també està acabada. Com a exemple, la figura 9 mostra la interfície del temps de reacció electiu.

La figura 10 mostra els resultats de les proves de temps de reacció amb la mostra de 10 subjectes. Les errades en temps de reacció electiu (pitjar el botó quan es produeix un estímul negatiu) no han estat incloses en el còmput de resultats. L'anàlisi de la variància mostra diferències significatives entre els tres grups $(p$ $=0)$. Comparant el visual amb l'auditiu, també es troben diferències estadísticament significatives $(\mathrm{p}=0)$. Els millors valors de temps de reacció auditiu respecte al visual concorden amb Pain i Hibbs (2007); aquests autors afirmen que el temps de reacció auditiu sempre és el més ràpid. Les dades observades són pròximes a les de Thompson i col. (1992), que identifiquen el

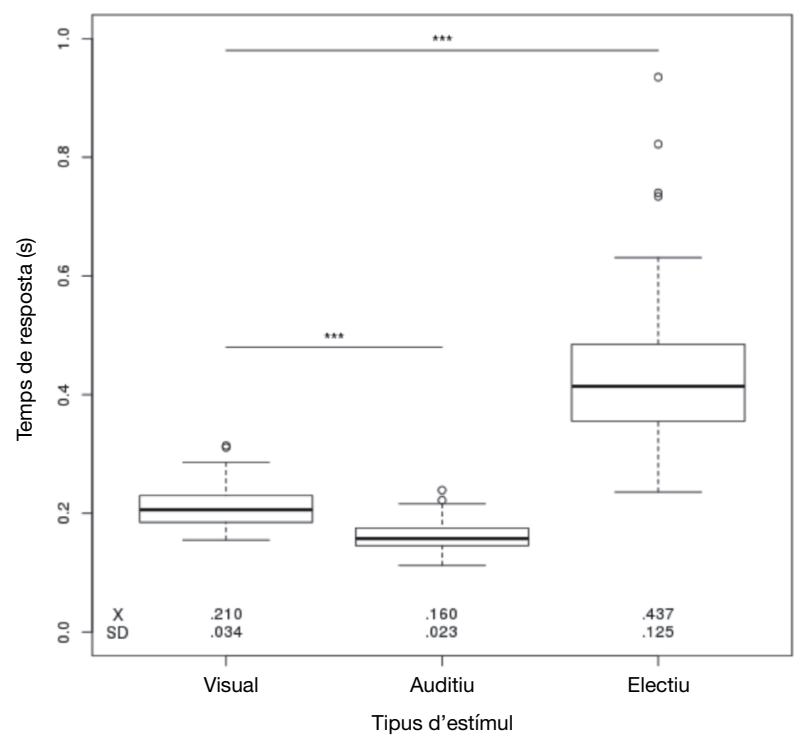

Figura 10. Resultats en segons en la prova de temps de reacció en funció del tipus d'estímul.

temps de reacció visual en 180-200 mil-lisegons, i l'auditiu en 140-160 mil-lisegons. Per altra banda, els resultats obtinguts són força més baixos que els de Shelton i Kumar (2010), 331 visual, 284 auditiu, probablement pel fet que aquests van usar un sistema que emetia i mesurava els temps de reacció a partir d'un ordinador personal, menys fiable -per culpa de la multitasca- que un microcontrolador. 


\section{Conclusió}

Les eines desenvolupades constitueixen una aportació significativa a les ciències de l'esport en l'àrea de la tecnologia esportiva. Les tres aportacions tenen encara marge per a la millora: En el cas del sistema de centralització de dades a partir de miniordinadors, cal optimitzar el programa perquè sigui més ràpid en algunes de les funcions, cosa que anirà acompanyada de les previsibles millores del maquinari que s'ha avaluat. Quant a l'aportació vinculada a l'accelerometria, cal calibrar i corregir el senyal provinent del moviment humà. En darrer lloc, les eines vinculades al temps de reacció requereixen la fabricació d'una placa PCB de disseny industrial i breus adaptacions en el firmware.

El present treball reivindica el paper de la tecnologia esportiva com a part del currículum de les ciències de l'esport. Les aportacions realitzades són públiques i, per tant, no tan sols el projecte Chronojump pot gaudir d'aquestes. En els pròxims mesos s'espera que els mateixos autors i d'altres col-laboradors que puguin aparèixer, les millorin, les adaptin a les seves necessitats i les comparteixin.

\section{Agraïments}

Volem a agrair a Carles Pina la seva orientació en la primera part del treball i a Josep Ma Padullés el seu suport en les altres dues parts.

\section{Referències}

Badiella, L. (2015). Manual de Introducción a Deducer: una interfaz gráfica para usuarios de $\mathrm{R}$ (5 ed.) [Manual de programari]. Recuperat a http://sct.uab.cat/ estadistica/sites/sct.uab.cat.estadistica/files/Manual\%20curs\%20Deducer.pdf

Beisey, D. \& Peaseley, V. (1937). The Relation of Reaction Time, Speed, and Agility of Big Muscle Groups to Certain Sport Skills. Research Quaterly, 8, 133-142. DOI: http://dx.doi.org/10.1080/23267402.1937.107 61808

Casartelli, N., Müller, R. \& Maffiuletti, N.A. (2010). Validity and reliability of the myotest accelerometric system for the assessment of vertical jump height. Journal of Strength and Conditioning Research 24.11. DOI: http://dx.doi.org/10.1519/JSC.0b013e3181 d8595c

Chronojump (2016). Chronojump - About us. Recuperat a http://chronojump.org/about.html

CRAN Comprehensive R Archive Network (2016). Contributed Packages. Recuperat a https://cran.rproject.org/web/packages/

Creative Commons (n.d.). Atribución-CompartirIgual 2.5 España. Recuperat a http://creativecommons.org/ licenses/by-sa/2.5/es/legalcode.es

Cruz, L. \& García, M. (1991). Fatiga psíquica en judokas mediante el flicker y el Tolouse-Pieron. Boletín Científico Técnico INDER 26(3), 11-26.

De Blas, X. (2005). Primeres aproximacions a la creació d'un mètode de mesua, gestió i estadística de la ca- pacitat de salt a partir de l'avaluació de temps de vol i temps de contacte en una plataforma de contactes amb programari i maquinari lliure. Projecte ChronoJump. Aloma: revista de psicologia, ciències de l'educació i de l'esport, (15), 107-124. Recuperat a http://www. raco.cat/index.php/Aloma/article/view/98155/154392

De Blas, X (2012). Proyecto Chronojump-Boscosystem. Herramienta informática libre para el estudio cinemático del salto vertical: medición del tiempo, detección del ángulo de flexión sin marcadores y elaboración de tablas de percentiles (Tesi doctoral). Recuperat a http://www. tdx.cat/handle/10803/83302

Duarte G. R. C. (2010). Personal trainer system. Recuperat a https://fenix.tecnico.ulisboa.pt/downloadFile/395142120768/resumo.pdf

Fox, J. \& Andersen, R. (2005). Using the R Statistical Computing Environment to teach Social Statistics Courses. Recuperat a http://www.unt.edu/rss/Teachingwith-R.pdf

Gandrud, C. (2013). Reproducible Research with $R$ and $R$ Studio ( $2^{\mathrm{a}}$ ed.). CRC Press. Recuperat a https://englianhu.files.wordpress.com/2016/01/reproducible-research-with-r-and-studio-2nd-edition.pdf

GNU (1991). GNU General Public License, version 2. Recuperat a http://www.gnu.org/licenses/old-licenses/gpl-2.0.html

Henry, F. \& Rogers, D. (1960). Increased Response Latency for Complicated Movements and A «Memory Drum» Theory of Neuromotor Reaction. Research Quaterly, 31, 448-458. DOI: http://dx.doi.org/10.10 80/10671188.1960.10762052

Hernández, S. \& Cuevas, J.H. (2013). Programas Informáticos de Uso Libre y su Aplicación en la enseñanza de la Estadística. Revista Investigacion Operacional, 34(2), 166-174. Recuperat a http://rev-inv-ope.univparis1.fr/files/34213/34213-08.pdf

Herrekor. (2015). BEI Ideacod. Encoders. Generadores de impulsos. Recuperat a http://www.herrekor.es/beiideacod-encoders-absolutos-incrementales/?gclid=C KbnnYXuzMECFamWtAodrUYAyQ

Himanen, P. (2001). La ética del hacker y el espíritu de la era de la información. Barcelona: Destino. Recuperat a http://eprints.rclis.org/12851/1/pekka.pdf?goback=. gde_4656878_memb

Intille, SS., Lester, J., Sallis, JF. \& Duncan, G. (2012). New Horizons in Sensor Development. Medicine \& Science in Sports \& Exercise, 44(1), 24-31. DOI: http:// dx.doi.org/10.1249/MSS.0b013e3182399c7d

Malley, L. (2014). Health, Fitness, Neoliberalism and Niche Markets: Does Planet Finess Deliver. Recuperat a http://qspace.library.queensu.ca/dspace/bitstream/1974/8621/1/Malley_Liah_D_201401_MA.pdf

Nakamura, H. (1934). An experimental Study of Reaction Time of the Start in Running a Race. Research Quarterly, 5, 33-45. DOI: http://dx.doi.org/10.1080/ 23267402.1934.10761656

Pain, M. T. \& Hibbs, A. (2007). Sprint starts and the minimum auditory reaction time. Journal of sports sciences, 25(1), 79-86. DOI: http://dx.doi.org/10.1080/ 02640410600718004 
Picerno, P., Camomilla, V. \& Capranica, L. (2011). Countermovement jump performance assessment using a wearable 3D inertial measurement unit. Journal of Sports Sciences 29.2, 139-146. DOI: http:// dx.doi.org/10.1080/02640414.2010.523089

Renishaw. (2015). Sistema de encóder angular RESM TONiC TM. Recuperat a http://www.renishaw.es/es/ sistema-de-encoder-angular-resm-tonic--10243

Roca, J. (1983). Tiempo de reacción y deporte. Barcelona: Generalitat de Catalunya, INEF.

$\mathrm{R}$ Team (2014). RStudio: integrated development for $R$ [Programari]. Recuperat a http://www.RStudio.com/ide.

Santos, A. \& Garatachea, N. (2012). Tendencias actuales de la acelerometría para la cuantificación de la actividad física. Revista Iberoamericana de Ciencias de la Actividad Física y el Deporte, 1(1), 24-32. Recuperat a http://dspace.uma.es/xmlui/bitstream/handle/10630/5373/Accelerometria-2.pdf?sequence $=1$

Schmidt, R. (1991). Motor learning and performance: From principles to practice. Champaign, Illinois: Human Kinetics.

Schmidt, R. \& Lee, T. (2011). Motor control and learning: $A$ behavioral emphasis ( $\left.5^{\text {a ed}}\right)$. Champaign, Illinois: Human Kinetics.

Shelton, J. \& Kumar, G. P. (2010). Comparison between auditory and visual simple reaction times. Neuroscience and Medicine, 1(1), 30. DOI: http://dx.doi.org/ 10.4236/nm.2010.11004

Solé, J., Quevedo, Ll., Augué, M. \& Morales, J. M. (2004). El control del entrenamiento de la resistencia: importancia de la frecuencia crítica de fusión ocular. Apunts. Educación física y deportes, 2(76), 28-34.

Stallman, R. \& col. (2002). Free Software Free Society: Selected Essays of Richard M. Stallman (3 ${ }^{\text {a }}$ ed.). Lulu. com. Recuperat a https://www.gnu.org/doc/fsfs3paperback.pdf

Technogym. (2014). The Wellness Company. Recuperat a http://www.technogym.com/es/

Thompson, P. D., Colebatch, J. G., Brown, P., Rothwell, J. C., Day, B. L., Obeso, J. A. \& Marsden, C. D. (1992).
Voluntary stimulus-sensitive jerks and jumps mimicking myoclonus or pathological startle syndromes. Movement Disorders, 7(3), 257-262. DOI: http://dx.doi. org/10.1002/mds.870070312

Thompson, W. R. (2013). NOW TRENDING : Worldwide Survey of Fitness Trends for 2014. ACSM'S Health \& Fitness Journal, 17(6), 10-20. Recuperat a http:// www.whatsnewinfitness.com.au/wp-content/ uploads/2014WorldwideTrends.pdf

WayCon. (2015). WayCon Positionsmesstechnik - Encoders. Recuperat a http://www.waycon.biz/products/ encoders/?gclid=CL7Uu4buzMECFVDKtAod8AEABQ Woodworth, R. \& Scholosberg, H. (1954). Tiempo de reacción. Buenos Aires, Argentina: Eudeba.

Redes, accelerometría y anticipación en el deporte dentro del entorno libre Chronojump

Resumen. El proyecto Chronojump se inició como una solución para la medida del salto vertical a partir de plataforma de contactos. Posteriormente se integraron fotocélulas y encoders. Debido a la naturaleza libre del proyecto, es viable añadir funcionalidades que en el mercado privativo son incompletas y costosas. Las soluciones que se desarrollan son: un entorno centralizado de datos de diferentes estaciones de trabajo en gimnasios / clubes, un dispositivo de acelerometría triaxial y un sistema para la medida del tiempo de reacción electivo, anticipación y flicker. Los métodos son: entrevistas a expertos, desarrollo de acelerómetro y dispositivos para la medida del tiempo de reacción, pruebas de velocidad y temperatura en miniordenadores, pruebas ideales y manuales del acelerómetro, pruebas de la velocidad de los leds en el dispositivo de anticipación, y pruebas de anticipación en una muestra. Los resultados indican que el miniordenador óptimo es el Raspberry Pi; se encuentran valores perfectos en acelerometría ideal pero incorrectos en la manual debido a la impureza del movimiento humano; el error en la velocidad de los leds en anticipación es de 0,03\%, y se encuentran diferencias significativas entre los grupos visual, auditivo y electivo. Las tres aportaciones son públicas par facilitar la investigación en las ciencias del deporte.

Palabras clave: Chronojump; Software libre; Red; Acelerometría; Tiempo de reacción 